Article

\title{
Control of Suitability of the Culture Daphnia magna Straus for Bioassays of Aquatic Environments, Taking into Account Demographic Indicators of Model Populations
}

\author{
Anna Olkova
}

Citation: Olkova, A. Control of Suitability of the Culture Daphnia magna Straus for Bioassays of Aquatic Environments, Taking into Account Demographic Indicators of Model Populations. Water 2021, 13, 47. https://doi.org/10.3390/w13010047

Received: 10 November 2020 Accepted: 1 December 2020 Published: 29 December 2020

Publisher's Note: MDPI stays neutral with regard to jurisdictional clai$\mathrm{ms}$ in published maps and institutional affiliations.

Copyright: () 2020 by the author. Licensee MDPI, Basel, Switzerland. This article is an open access article distributed under the terms and conditions of the Creative Commons Attribution (CC BY) license (https:// creativecommons.org/licenses/by/ $4.0 /)$.
Department of Ecology and Nature Management, Vyatka State University, 610001 Kirov, Kirov Region, Russia; morgan-abend@mail.ru

\begin{abstract}
The purpose of this work was to experimentally determine conditional reference demographic indicators of laboratory populations of Daphnia magna Straus (1820). These indicators can be used when determining suitability of the aquaculture for bioassays of aquatic environments. The experiments were carried out with parthenogenetic clones of D. magna, the temperature of the environment was $20{ }^{\circ} \mathrm{C}$, the light period was $12 \mathrm{~h}$. It was found that the maximum lifetime of crustaceans is observed in groups with a density of 25 individuals $/ \mathrm{dm}^{3}$. In these groups, other demographic characteristics of $D$. magna such as the day of the first offspring (10 \pm 2 days), average lifetime (79.7 \pm 1.0 days), specific fertility $(74.3 \pm 2.4$ days $)$ and other related parameters of wellbeing were established. Then, it was showed that the culture of D. magna, having the necessary sensitivity to the model toxicant $\mathrm{K}_{2} \mathrm{Cr}_{2} \mathrm{O}_{7}$, can significantly differ in demographic characteristics from the conventional reference groups. Audit of the conditions of keeping this aquaculture revealed a complex reason for the unsatisfactory state of D. magna: the lack of daily aquaculture care and increased concentration of nitrate ions in the cultivation water. Therefore, regular monitoring of D. magna demographic characteristics can complement procedures of standardization of test-cultures. This will contribute to improving the accuracy of bioassay results.
\end{abstract}

Keywords: bioassay; test culture; Daphnia magna; test conditions; fertility; lifetime

\section{Introduction}

At present, the pollution of environmental components is characterized by the appearance of new toxicants (nanomaterials, new polymers, medical substances), multicomponent emissions and discharges, the transformation of pollutants in the air, water and soil, and other complex processes. Therefore, the need to combine chemical methods and bioassays is a generally recognized trend in planning environmental studies [1-3]. Bioassays allow one to determine the integral toxicity of the studied environment and extrapolate the data obtained to real ecosystems. At the same time, it is necessary to take into account the sensitivity of various biological species to toxicants, the adaptive capabilities of organisms in the environment, as well as the action of a complex of abiotic and biotic factors.

The objectivity of bioassay results largely depends on the level of "reliability" of the test cultures used. Scientists at Moscow State University (Moscow, Russia) propose to solve the problem of providing bioassay laboratories with standardized test cultures by forming a single national bank of test cultures, which would guarantee that the test culture meets the specified criteria [4].

It is known that many indicators of the vital activity of organisms and their responses to toxicants depend on environmental factors. For example, the authors of [4] discus problems of choosing water for cultivation and dilution of the tested media and influence of temperature conditions and lighting on the test culture. The scientists investigate the influence of cultivation conditions on test cultures such as fungi [5,6], bacteria [7], echinoderms [8] and other organisms. 
The methodology of standardization of aquacultures and their parameters is an urgent scientific and applied problem [9]. In solving this problem, it is necessary to start with aquacultures used for bioassays around the world. The laboratory cultures D. magna are widely used in scientific research, including according to standardized test protocols [10-13].

Back in 1986, in a large-scale study on the example of biotests for D. magna reactions, it was shown that out of 37 laboratories, 15 did not meet the reliability criteria based on the results of the "ring test" procedure. [14]. The modern analogue of the "ring test" procedure is interlaboratory comparative tests of the same sample. The problem of variability in response is associated with insufficient consideration of many factors affecting the result of a toxicological test [15]. The authors [15] divide the total variability in stress-response of a group of test animals into three subcomponents: the variability due to genetic heterogeneity, the variability due to environmental heterogeneity, the variability due to genotype interaction with the environment. The importance of the individual characteristics of test organisms is also confirmed by the example of collembolans. It turned out that the difference in $1{ }^{\circ} \mathrm{C}$ during the experiment does not have a noticeable effect, but the difference of the use of collembolans in one day affects the final result of the bioassay [16].

Undoubtedly, demographic characteristics of $D$. magna laboratory groups will fluctuate in response to such factors as the season, the chemical composition of cultivation water, and can be specified for certain conditions [4,17]. The work in [18] showed that differences in the density of model populations of D. magna and the temperature of their storage lead to the variability of the maturation time, lifetime, fertility, and affect the dynamics of the reproduction process. At the same time, these parameters are assessed in many test organisms as test functions during biotests [11-13]. In works carried out under different experimental conditions, the obtained results differ from our data. Highly variable fertility of D. magna (30.3-74.6 fry per female) was shown when crustaceans were placed by 5 in $250 \mathrm{~mL}$ of water [19]. When growing one Daphnia in a cultivation vessel, the fertility varied from 17 to 67 fry per female [20].

Thus, it is necessary for each laboratory to conduct regular observations of the increased set of indicators of the "health" of aquacultures, compare them with reference values in other laboratories and with their own indicators accumulated during the observation period. In this case, the demographic characteristics, together with the determination of sensitivity to the model toxicant, will contribute to the strict control of the state of the D. magna culture and its suitability for biotesting of aquatic environments. This approach has already been successfully used in some bioassay protocols to control the sensitivity of the culture to the model toxicant [13].

The purpose of this work is to experimentally determine conditional reference demographic indicators of laboratory populations of $D$. magna which are intended to control the state of the aquaculture.

\section{Materials and Methods}

The presented study consisted of two stages (Figure 1). The work was carried out in certified laboratories.

In the first part of the work in Laboratory No. 1, conditional reference demographic indicators of the laboratory culture of $D$. magna were determined. It is known that lifetime is a universal criterion for well-being of individuals and their populations. [21]. The most prosperous populations with the maximum lifetime of individuals in the created conditions were found. To do this, 3 variants of model populations of D. magna were created, differing in the density of individuals in the aquatic habitat. Experimental groups were formed from juveniles of D. magna no more than $24 \mathrm{~h}$ old. The experiment continued until the end of the life of the last Daphnia from the group. The observed indicators of model groups of Daphnia are shown in Figure 1. The experiment was repeated three times to obtain reference values for demographic characteristics of D. magna. 


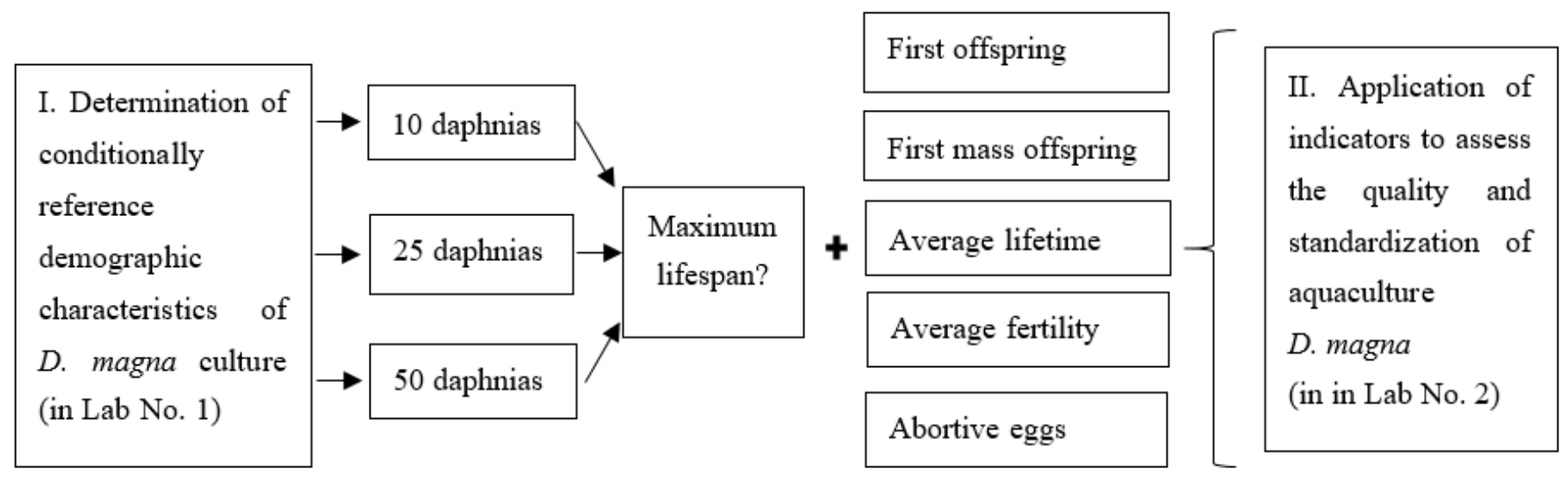

Figure 1. Research design.

In the second part of the work, the state of the D. magna culture in Laboratory No. 2. was examined. The employees of the laboratory regularly experience problems with the cultivation of D. magna and the use of crustaceans for biotests linked to the following: low fertility of individuals, the appearance of abortive eggs, the death of experimental Daphnia in control variants.

All model groups of Daphnia in Laboratory No. 1 and Laboratory No. 2 were kept in a climatic chamber $\left(20^{\circ} \mathrm{C}\right)$. Light period was $12 \mathrm{~h}$. Daphnia ate daily, the feed was a suspension of the algae Chlorella vulgaris Beij. (1890), and 2 times a week there was an addition of the yeast Saccharomyces cerevisiae Meyen ex E.C.Hansen (1883). The median lethal concentration of the model toxicant $\left(\mathrm{K}_{2} \mathrm{Cr}_{2} \mathrm{O}_{7}\right)$ at exposure for $24 \mathrm{~h}$ was found in the dose range of $0.9-2.0 \mathrm{mg} / \mathrm{dm}^{3}$. Daphnia reproduced in a parthenogenetic manner.

Drinking-quality artesian water was used for cultivation of D. magna. Daily care of the experimental groups of daphnia included the replacement of part of the aquatic habitat $(30 \%)$. The sources of cultivation water in Laboratory No. 1 and Laboratory No. 2 were different. The quality of cultivation water was regularly monitored (every 3 months), determining the most important indicators for D. magna. The content of metals (total) $\mathrm{Co}, \mathrm{Ni}, \mathrm{Cu}$, $\mathrm{Zn}, \mathrm{Cr}, \mathrm{Mn}, \mathrm{Fe}, \mathrm{Cd}$ and $\mathrm{Pb}$ was determined by the atomic absorption method [22]. Mass concentration of oil products was determined by infrared spectrophotometry [23]. The content of pesticides was determined: the gamma-isomer of hexachlorane, dichlorodiphenyltrichloroethane (the sum of isomers), hexachlorobenzene, and hexachlor [24]. The content of $\mathrm{Na}^{+}, \mathrm{K}^{+}, \mathrm{Ca}^{2+}, \mathrm{Mg}^{2+}, \mathrm{NH}_{4}{ }^{+}, \mathrm{Cl}^{-}, \mathrm{NO}_{3}{ }^{-}, \mathrm{SO}_{4}{ }^{-}, \mathrm{PO}_{4}{ }^{3-}$ ions was determined by the chromatographic method $[25,26]$.

The obtained results were subjected to mathematical processing with further presentation of the data in the form $\mathrm{M} \pm \mathrm{S}$, where $\mathrm{M}$ - the arithmetic mean, S-the standard deviation. The significance of the differences was assessed by the Student's t test with Bonferroni amendment for multiple comparisons. The overall significance level was accepted as 0.05 , and for paired comparisons as 0.017 in accordance with the Bonferroni method. To confirm or refute the relationship of various characteristics, the Pearson correlation coefficient $r$ was calculated.

\section{Results and Discussion}

\subsection{Determination of Conditional Reference Characteristics of Model Populations of D. magna}

The demographic indicators of the D. magna model groups significantly depended on the density of individuals in the habitat created at the beginning of the experiment (Table 1).

Lifetime and fertility are universal characteristics that show the general well-being of any population of living organisms. According to these criteria, a group of daphnia was distinguished, which at the beginning of the experiment consisted of 25 individuals in $1 \mathrm{dm}^{3}$. The population density of D. magna at the level of $20-25$ individuals $/ \mathrm{dm}^{3}$ is recommended by many bioassay methods [10-13]. 
Table 1. Variation of demographic characteristics of D. magna culture depending on the density of the model population.

\begin{tabular}{cccc}
\hline Demographic Characteristics & 10 Specimens/dm & 25 Specimens/dm & 50 Specimens/dm \\
\hline First offspring, day & $7 \pm 1$ & $10 \pm 2$ & $15 \pm 2$ \\
First mass offspring 1, day & $7 \pm 1$ & $18 \pm 2$ & $18 \pm 2$ \\
Average lifetime, days & $41.7 \pm 4.7$ & $79.7 \pm 1.0$ & $58.9 \pm 5.7$ \\
Maximum duration of life, days & $72.0 \pm 9.8$ & $114.0 \pm 1.7$ & $92.0 \pm 9.1$ \\
Average fertility, pcs./1 adult female & $153.6 \pm 33.7$ & $74.3 \pm 2.4$ & $51.2 \pm 1.0$ \\
Number of abortive eggs, pcs. & 0 & 0 & $6 \pm 1$ \\
\hline
\end{tabular}

${ }^{1}$ The day of the first mass offspring is recorded when the detected number of juveniles is 2 or more times greater than the number of adult females.

The average and maximum lifetime of crustaceans at their optimum density is significantly higher than in the options " 10 individuals $/ \mathrm{dm}^{3}$ " by 1.9 and 1.6 times, respectively, and compared with the option " 50 individuals $/ \mathrm{dm}^{3}$ " is higher by 1.4 and 1.2 times, respectively. All differences between the options are statistically significant at the aforementioned level $(p<0.017)$, except for the difference in the maximum life dutation between the options " 10 individuals per $1 \mathrm{dm}^{3 "}$ and " 50 individuals per $1 \mathrm{dm}^{3}$ ". Consequently, both low and high population density lead to reduction in lifetime. This effect is correlated with the ability of individuals to reproduce.

The differences between $D$. magna females belonging to different groups were observed since the formation of brood chambers. In daphnia from groups of " 10 individuals $/ \mathrm{dm}^{3}$ ", eggs in brood chambers were noticeable already on the fifth day of their life, and in groups

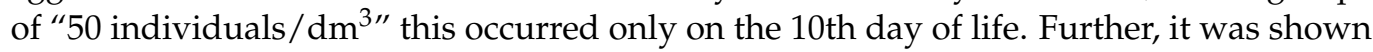
that the high density of the D. magna population led to a delay in the appearance of the first juveniles and a shift in the period of increased fertility. As a result, the group with an initial density of 50 individuals $/ \mathrm{dm}^{3}$ had the lowest specific fertility per female. It should be noted that the level equal to $51.2 \pm 1.0$ was achieved mainly due to crustaceans that survived in the second half of the experiment (more than 30 days old), when there was natural decrease in density due to the death of some individuals in the model population.

The maximum fertility of $D$. magna was observed in groups with the density of 10 individuals $/ 1 \mathrm{dm}^{3}$. The indicator was 2.1 times and three times higher than in " 25 individuals $/ \mathrm{dm}^{3 \text { " }}$ and "50 individuals $/ \mathrm{dm}^{3}$ " variants, respectively. However, it was already discussed that low density groups had the shortest lifetime. The obtained results indicate the depletion of crustaceans as a result of high fertility caused by the large volume of habitat per 1 individual. On the contrary, too high a density of model groups does not allow crustaceans to realize their fertile potential. This confirms that the demographic characteristics set for the group "25 individuals $/ \mathrm{dm}^{3}$ " can be used as a conditional reference.

\subsection{Control of Suitability of the Aquaculture D. magna for Bioassay of Aquatic Environments}

Received conditional reference demographic indicators of the culture D. magna in Laboratory No. 1 were used to assess the state of the culture of crustaceans in Laboratory No. 2 (Table 2).

It was noted above that in Laboratory No. 2, there were problems both during cultivation of $D$. magna, and in the process of the bioassay. It turned out that many important characteristics of the model populations of $D$. magna differ significantly from the conditional reference indicators obtained experimentally in Laboratory No. 1. The appearance of the first juveniles and the beginning of mass reproduction were delayed by a week or more. The lifetime reduced in two parameters by $50-70 \%$ and fertility fell by more than three times. The appearance of abortive eggs, which is also a sign of the unfavorable state of the D. magna culture, was also observed.

Against the background of these negative phenomena, sensitivity of D. magna culture to a model toxicant $\left(\mathrm{K}_{2} \mathrm{Cr}_{2} \mathrm{O}_{7}\right)$ regularly fell within the generally accepted range of $0.9-2.0 \mathrm{mg} / \mathrm{dm}^{3}$. This fact confirms the insufficiency of this criterion to determine the suitability of the test culture for bioassay purposes. 
Table 2. Demographic characteristics of D. magna cultures in two bioassay laboratories.

\begin{tabular}{ccc}
\hline Demographic Characteristics. & $\begin{array}{c}\text { Laboratory No. } \\
\text { 1-Conditional Standard }\end{array}$ & Laboratory No. 2 \\
\hline First offspring, day & $10 \pm 2$ & $17 \pm 2$ \\
First mass offspring, day & $18 \pm 2$ & $27 \pm 3$ \\
Average lifetime, days & $79.7 \pm 1.0$ & $46.6 \pm 2.3$ \\
Maximum duration of life, days & $114.0 \pm 1.7$ & $74.0 \pm 2.1$ \\
Average fertility, pcs./1 adult female & $74.3 \pm 2.4$ & $21.4 \pm 3.5$ \\
Range $\mathrm{LD}_{50}\left(\mathrm{~K}_{2} \mathrm{Cr}_{2} \mathrm{O}_{7}\right)$ for 6 months & $1.3-1.7$ & $0.95-1.9$ \\
Number of abortive eggs, pcs. & 0 & $11.7 \pm 4.5$ \\
\hline
\end{tabular}

Further, in order to determine the possible reasons for the unsatisfactory state of D. magna culture in Laboratory No. 2, the audit of the factors that most often affect aquatic organisms under laboratory conditions was carried out (Table 3).

Table 3. Analysis of abiotic and biotic conditions of D. magna in Laboratory No. 2.

\begin{tabular}{ccc}
\hline Conditions & Meaning & Conclusion \\
\hline $\begin{array}{c}\text { Temperature of stock }{ }^{1} \text { culture } \\
\text { keeping }\end{array}$ & $20^{\circ} \mathrm{C}$ (climatic chamber) & Normal \\
\hline $\begin{array}{c}\text { Temperature of synchronized } \\
\text { culture keeping }\end{array}$ & $20^{\circ} \mathrm{C}$ (climatic chamber) & Normal \\
\hline Light period & $12 \mathrm{~h}$ (climatic chamber) & Normal \\
\hline Regularity of feeding & Daily, except weekends & Not satisfactory \\
\hline Variety of feed & Only Ch. vulgaris & Not satisfactory \\
\hline Density of stock ${ }^{1}$ culture & Not controlled & Not satisfactory \\
\hline $\begin{array}{c}\text { Density of a synchronized culture } \\
\text { Frequency of removal of juveniles } \\
\text { from aquacultures }\end{array}$ & 20-25 individuals/dm ${ }^{3}$ & Normal \\
\hline $\begin{array}{c}\text { Control of the chemical composition } \\
\text { of cultivation water }\end{array}$ & Reekends & Not satisfactory \\
\hline
\end{tabular}

${ }^{1}$ A stock culture is a collection of individuals of different ages, which reproduce in a way and simulate the natural population. ${ }^{2}$ A synchronized culture is a set of individuals of the same age obtained from one female from a stock culture by acyclic parthenogenesis in the third generation.

In Laboratory No. 2, D. magna culture is kept in the climatic chamber, which is the obligatory requirement in bioassay protocols [10-13]; however, many laboratories still ignore this condition. From the data in Table 3, we see that the observed D. magna culture needs more regular maintenance. The staff of Laboratory No. 2 pay little attention to stock culture, since it is not used directly in the experiment. However, maintaining its well-being is very important, since individuals of such populations, which are closest to natural ones, should form groups of crustaceans, the juveniles of which will be used in biotests. Removing juveniles every other day is not acceptable, since juveniles significantly reduce the food supply for adults and oppress them. Feeding Daphnia with only one type of food also affects them negatively. The introduction of baker's yeast into the nutrition of Daphnia provides them with the necessary protein. For example, the work in [27] showed that the morphological parameters of Daphnia, as well as clutch size, egg volume and postembryonic development time, depend on the variety and quality of feed.

The chemical composition of cultivation water is one of the most important factors in maintaining the aquaculture in satisfactory conditions [28,29]. The results of control of the composition of water used in Laboratory No. 2 were analyzed. No toxic substances in the water (oil products, heavy metals, pesticides) were found. The mean of concentrations of ions that exceed Russian environmental standards in some seasons are shown in Table 4. 
Table 4. The content of some ions in the cultivation water in Laboratory No. 2.

\begin{tabular}{cccc}
\hline Season & $\mathbf{M g}^{\mathbf{2 +}}$ & $\mathbf{N O}_{\mathbf{3}^{-}}$ & $\mathbf{S O}_{4}{ }^{\mathbf{2}}$ \\
\hline winter & $49 \pm 5$ & $53 \pm 8$ & $117 \pm 12$ \\
spring & $41 \pm 4$ & $45 \pm 7$ & $106 \pm 11$ \\
summer & $40 \pm 4$ & $50 \pm 8$ & $101 \pm 10$ \\
autumn & $41 \pm 9$ & $51 \pm 8$ & $105 \pm 11$ \\
MPC $^{1}$ & 40.0 & 40.0 & 100.0 \\
\hline
\end{tabular}

1 The maximum permissible concentration (MPC) is the environmental standard of the Russian Federation, intended for fishery water bodies.

Significant excess of the Russian maximum permissible concentration (MPC) standard was not found. The established excess of a part was within the error of the methods of chemical analysis. However, the correlation analysis of the relationship between the concentration of ions and $\mathrm{LD}_{50}\left(\mathrm{~K}_{2} \mathrm{Cr}_{2} \mathrm{O}_{7}\right)$ showed interrelation (Table 5).

Table 5. Influence of the content of nitrate anions on the sensitivity of $D$. magna to a model toxicant.

\begin{tabular}{cccc}
\hline Season & Multiplicity $\left(\mathbf{N O}_{\mathbf{3}}{ }^{-}\right)$to $\mathbf{M P C}$ & $\mathbf{L D}_{\mathbf{5 0}}\left(\mathbf{K}_{\mathbf{2}} \mathbf{C r}_{\mathbf{2}} \mathbf{O}_{\mathbf{7}}\right)$ & Pearson Coefficient \\
\hline winter & 1.30 & 0.95 & \\
spring & 1.10 & 1.9 & -0.9 \\
summer & 1.25 & 1.5 & \\
autumn & 1.28 & 1.1 & \\
\hline
\end{tabular}

It is shown that the more nitrates water contains, the more sensitive D. magna is to the toxicant, $r=-0.9$. Earlier it was demonstrated that the fertility of $D$. magna changes in response to the presence of mineral nitrogen compounds in water [30]. Most often, such direct relationships cannot be identified, since the effects of mixtures of several toxicants are manifested [3].

The results of the work done in Laboratory No. 2 showed the reasons for the unsatisfactory state of the D. magna culture in comparison with the accepted conventional standard. The first reason is the lack of daily aquaculture care and the monotonous diet. The second reason is the increased content of nitrates in cultivation water. Correcting of these factors will improve the "health" of D. magna in model populations.

\section{Conclusions}

The results of this work confirmed that it is not enough to determine the readiness of the test culture for bioassay only by its sensitivity to the model toxicant. Using D. magna as an example, it was shown that despite the satisfactory sensitivity to potassium dichromate, the unsatisfactory state of individuals in the aquaculture is observed. This can be caused not only by abiotic factors of the cultivation of organisms (lighting, temperature, chemical composition of water), but also by biotic parameters controlled by the operators of biotests.

It was experimentally established that under optimal cultivation conditions (temperature $20{ }^{\circ} \mathrm{C}$ and density of groups 25 individuals $/ \mathrm{dm}^{3}$ ), the operational criterion for suitability of $D$. magna for biotesting is the "first offspring" - $10 \pm 3$ days. Over the full life cycle of $D$. magna individuals, the following demographic characteristics of $D$. magna were determined: average lifetime (79.7 \pm 1.0 days), maximum duration of life of an individual in a group $(114.0 \pm 1.7$ days $)$, average fertility individuals $(74.3 \pm 2.4)$. It is recommended to evaluate the "first offspring" indicator for each synchronized group of D. magna. The indicators that are determined for the full life cycle of crustaceans must be monitored once every six months.

It is advisable to control the suitability of many test cultures of meso- and macroorganisms in terms of the time of maturity, the time of the first offspring, specific fertility, as well as the average and maximum lifetime of individuals. Their experimental determination and implementation in bioassay practices represents the direction of our future research. 
Funding: This research received no external funding.

Conflicts of Interest: The author declares no conflict of interest.

\section{References}

1. Directive 2000/60/EC of the European Parliament and of the Council Establishing a Framework for the Community Action in the Field of Water Policy-EU Water Framework Directive (as Amended on 20 October 2014). 2000. Available online: https: / / eur-lex.europa.eu/legal-content/EN/TXT/?uri=CELEX:32000L0060 (accessed on 14 September 2020).

2. Water Code of the Russian Federation (as Amended on 27 December 2018). 2006. Available online: http://docs.cntd.ru/ document/901982862 (accessed on 15 October 2020).

3. Altenburger, R.; Scholze, M.; Busch, W.; Escher, B.; Jakobs, G.; Krauss, M.; Krueger, J.; Neil, P.; Ait-Aissa, S.; Almeida, A.C.; et al. Mixture effects in samples of multiple contaminants-An inter-laboratory study with manifold bioassays. Environ. Int. 2018, 114, 95-106. [CrossRef] [PubMed]

4. Terekhova, V.A.; Wadhia, K.; Fedoseeva, E.V.; Uchanov, P.V. Bioassay standardization issues in freshwater ecosystem assessment: Test cultures and test conditions. Knowl. Manag. Aquat. Ecosyst. 2018, 419, 32. [CrossRef]

5. Ortiz-Urquiza, A.; Keyhani, N.O.; Quesada-Moraga, E. Culture conditions affect virulence and production of insect toxic proteins in the entomopathogenic fungus Metarhizium anisopliae. Biocontrol Sci. Technol. 2013, 23, 1199-1212. [CrossRef]

6. Skalicky, A.; Bohata, A.; Simkova, J.; Osborne, L.S.; Landa, Z. Selection of indigenous isolates of entomopathogenic soil fungus Metarhizium anisopliae under laboratory conditions. Folia Microbiol. 2014, 59, 269-276. [CrossRef] [PubMed]

7. Yi, X.W.; Gao, Z.Q.; Liu, L.H.; Zhu, Q.; Hu, G.J.; Zhou, X.H. Acute toxicity assessment of drinking water source with luminescent bacteria: Impact of environmental conditions and a case study in Luoma Lake, East China. Front. Environ. Sci. Eng. 2020, 14, 109. [CrossRef]

8. Schipper, C.A.; Dubbeldam, M.; Feist, S.W.; Rietjens, I.M.C.M.; Murk, A.J. Cultivation of the heart urchin Echinocardium cordatum and validation of its use in marine toxicity testing for environmental risk assessment. In Assessment of Effects of Chemical Contaminants in Dredged Material on Marine Ecosystems and Human Health; Book Series: Deltares Select Series; IOS Press: Amsterdam, The Netherlands, 2009; Volume 6, pp. 55-66.

9. Olkova, A.S. Modern trends in the development of the methodology of bioassay aquatic environments. Theor. Appl. Ecol. 2018, 3, 19-26. [CrossRef]

10. ISO 6341:2012. Water Quality—Determination of the Inhibition of the Mobility of Daphnia Magna Straus (Cladocera, Crustacea)— Acute Toxicity Test; International Organization for Standardization: Geneva, Switzerland, 2012; 22p, Available online: https: //www.iso.org/standard/54614.html (accessed on 15 October 2020).

11. OECD Guidelines for the Testing of Chemicals, Section 2. Test No. 202: Daphnia sp. Acute Immobilisation Test; OECD Publishing: Paris, France, 2004; 12p, Available online: https://www.oecd-ilibrary.org/environment/test-no-202-daphnia-sp-acute-immobilisationtest_9789264069947-en (accessed on 6 November 2020).

12. Federal Register FR 1.39.2007.03222. Methodology for Determining the Toxicity of Water and Water Extracts from Soils, Sewage Sludge, and Waste by Mortality and Changes in Fertility of Daphnias; Akvaros: Moscow, Russia, 2012; 51p.

13. Biological Test Method: Acute Lethality Test Using Daphnia spp. EPS 1/RM/12. Report; Environment Canada: Ottawa, ON, Canada, 1990; Available online: https://www.canada.ca/content/dam/eccc/migration/main/faunescience-wildlifescience/dfad4a5b4216-4ed8-af90-98a6de8f7b6b/rm11e.pdf (accessed on 15 October 2020).

14. Cabridenc, R. Exercice D'intercalibration Concernant une Méthode de Détermination de L'ecotoxicité à Moyen Terme des Substances Chimiques vis-à-vis des Daphnies; Unpublished EC Report; Contract W/63/476 (214). Ref. I.R.C.H.A.D. 8523; Institut National de Recherche Chimique Appliquee: Vert-le-Petit, France, 1986; 20p.

15. Baird, D.J.; Barber, I.; Bradley, M.; Calow, P.; Soares, A.M.V.M. The Daphnia bioassay: A critique. Hydrobiologia 1989, 188, $403-406$. [CrossRef]

16. Crouau, Y.; Cazes, L. What causes variability in the Folsomia candida reproduction test? Appl. Soil Ecol. 2003, 22, 175-180. [CrossRef]

17. Olkova, A.S. Health monitoring of Daphnia magna Straus test culture. Water Ecol. Probl. Solut. 2019, 3, 50-69. [CrossRef]

18. Olkova, A.S.; Kantor, G.Y.; Kutyavina, T.I.; Ashikhmina, T.Y. The importance of maintenance conditions of Daphnia magna Straus as a test organism for ecotoxicological analysis. Environ. Toxicol. Chem. 2018, 37, 376-384. [CrossRef] [PubMed]

19. Vorob"eva, O.V.; Filenko, O.F.; Isakova, E.F. Changes in the fertility of the laboratory culture D. magna. Perspect. Sci. 2013, 9, $11-14$.

20. Misejko, G.N.; Tushkova, G.I.; Ckhaj, I.V. Daphnia magna (Crustacea Cladocera) as a test-object under optimal laboratory cultivation conditions. Izv. Altaj. Gos. Univ. 2001, 3, 83-86.

21. Odum, E.P. Fundamentals of Ecology, 3rd ed.; W. B. Saunders Co.: Philadelphia, PA, USA, 1971; 574p.

22. PND F 14.1:2:4.139-98. Environmental Regulatory Document. Method for Measuring Mass Concentrations Cobalt, Nickel, Copper, Zinc, Chrome, Manganese, Iron, Silver, Cadmium and Lead in Samples Drinking, Natural and Waste Water Method Atomic Absorption Spectrometry; FCAO: Moscow, Russia, 2010; Available online: https:/ / files.stroyinf.ru/Data2/1/4293832/4293832535.htm (accessed on 6 November 2020). 
23. Guidance Document RD 52.24.476-2007. Mass Concentration of Oil Products in Water. Procedure for Performance of Measurements by IK-Photometric Method; Hydrochemical Institute: Rostov-na Donu, Russia, 2007; Available online: https: / / files.stroyinf.ru/Data2 /1/4293837/4293837309.htm (accessed on 6 November 2020).

24. PND F 14.1:2:3:4.204-04. Environmental Regulatory Document. Measurement Procedure of Mass Concentrations of Organic Chlorous Pesticides and Polychlorinated Biphenyl in Drinking, Natural and Waste Water Gas Chromatographic Method; FCAO: Moscow, Russia, 2009; Available online: https:/ / files.stroyinf.ru/Data2/1/4293809/4293809643.htm (accessed on 6 November 2020).

25. Federal Register 1.31.2005.01724. Methods for Measuring the Mass Concentration of Fluoride, Chloride, Nitrate, Phosphate and Sulfate Ions in Samples of Drinking, Mineral, Table, Medical-Table, Natural and Waste Water by Ion Chromatography; Aquilon: Moscow, Russia, 2008; Available online: http:/ / www.prochrom.ru/ru/?id=4\&idp=met\&mode=mdesc (accessed on 6 November 2020).

26. Federal Register 1.31.2005.01738. Methods for Measuring the Mass Concentration of Ammonium, Potassium, Sodium, Magnesium, Calcium, Strontium Cations in Samples of Drinking, Mineral, Table, Medical-Table, Natural and Waste Water by Ion Chromatography; Aquilon: Moscow, Russia, 2008; Available online: http:/ / www.prochrom.ru/ru/?id=3\&idp=met.http://www.prochrom.ru/ru/ ?id=3\&idp=met (accessed on 6 November 2020).

27. Machacek, J. Daphnia galeata life history response to heterogeneous food conditions and dissolved chemicals in the Rimov Reservoir. Hydrobiologia 2001, 442, 215-222. [CrossRef]

28. Jonczyk, E.; Gilron, G. Acute and chronic toxicity testing with Daphnia sp. In Small-Scale Freshwater Toxicity Investigations; Volume 1 Toxicity Test Methods; Blaise, C., Férard, J.-F., Eds.; Springer Science \& Business Media: Amsterdam, The Netherlands, 2005; pp. 337-393.

29. Ol'kova, A.S. The conditions of cultivation and the variety of test functions of Daphnia magna Straus in bioassay. Water Ecol. Probl. Solut. 2017, 1, 64-82. [CrossRef]

30. Olkova, A.S.; Mahanova, E.V. Selection of bioassay for ecological research of water, polluted by mineral nitrogen forms. Water Ecol. Probl. Solut. 2018, 4, 70-81. [CrossRef] 